\title{
Biodiversidad en Ambientes Fragmentados de Chile: Patrones y Procesos a Diferentes Escalas
}

\author{
Audrey A. Grez, Javier A. Simonetti y Ramiro O. Bustamante (Editores)
}

La fragmentación y pérdida de hábitat son las causas más importantes de pérdida de biodiversidad en el mundo. Este libro recoge los avances teóricos, metodológicos y empíricos de los estudios realizados en Chile, en relación a estos fenómenos de creciente desarrollo, dado el incremento de la presión del hombre sobre la tierra. Los diferentes capítulos revelan los efectos de la fragmentación y pérdida de hábitat en una gran variedad de organismos, tales como insectos, moluscos, plantas y vertebrados. A pesar de que el libro presenta estudios sobre la experiencia chilena, conceptualmente sus conclusiones son aplicables a distintos lugares del mundo. Una de las novedades de este texto es que no sólo aborda ecosistemas naturales sino que también examina el fenómeno de fragmentación y pérdida de hábitat en agroecosistemas. Ello porque el diseño de los sistemas agrícolas, también puede ser relevante para el control biológico de plagas, puesto que algunos enemigos naturales se ven favorecidos en ambientes más fragmentados. Otro aspectos interesante que plantea esta obra, es que dado que la fragmentación se encuentra instalada en el paisaje chileno, los remanentes de vegetación nativa, que conservan biodiversidad, deben ser considerados en los planes de manejo de las zonas explotadas, ya que proveen hábitat para las especies y son importantes desde el punto de vista de conectividad del paisaje.

Esta publicación es una contribución crítica y muy importante a nuestro entendimiento sobre cómo conservar mejor la biodiversidad en paisajes donde la pérdida y fragmentación del hábitat son temas apremiantes.

Los editores son Audrey A. Grez, Javier A. Simonetti y Ramiro O. Bustamante, profesores de la Universidad de Chile, investigadores con una reconocida trayectoria científica.

Biodiversidad en Ambientes Fragmentados

de Chile: Patrones y Procesos a

Diferentes Escalas

Audrey A. Grez, Javier A. Simonetti y

Ramiro O. Bustamante (eds)

Editorial Universitaria.

Santiago, Chile

ISBN: 956-11-1912-9

232 p., 10 capítulos.

Formato: 17,4 x 24,6 cm

Fecha de publicación: diciembre, 2006

www.universitaria.cl

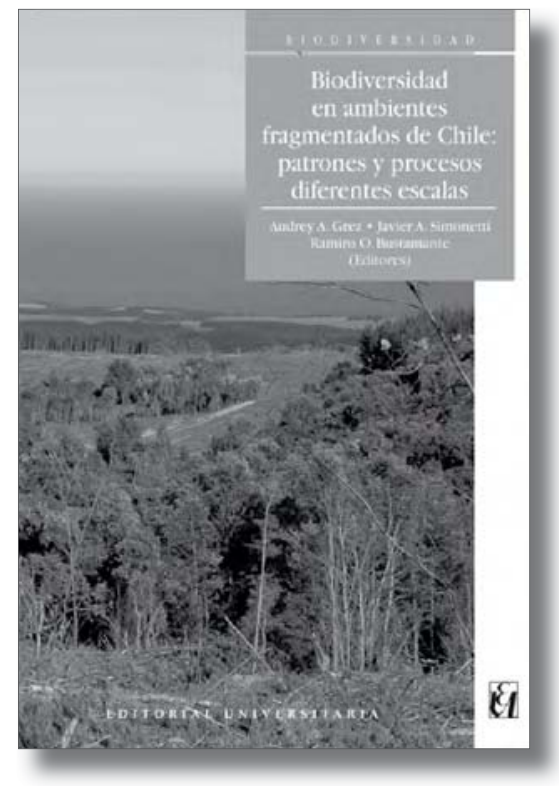

